\title{
Anil Hira, An East Asian Model for Latin American Success
}

\author{
the New Path, London: Ashgate, 2007.
}

\author{
Francisco E. González
}

Received: 1 September 2009 / Accepted: 1 September 2009 /

Published online: 11 December 2009

(C) Springer Science+Business Media B.V. 2009

This is a wide-ranging, well-documented, cogently-argued book, in the tradition of previous works that have spelled out the implications of East Asian countries' development success, based on effective state-led industrial policy, for the countries of Latin America. This two-region comparison has been shown to be fruitful analytically as well as empirically as evinced by now classic works such as Stephan Haggard's Pathways from the Periphery: the Politics of Growth in Newly Industrializing Countries (Cornell, 1990) and Alice Amsden's, The Rise of "the Rest": Challenges to the West from Late-Industrializing Economies (OUP, 2001). Such scholarly fruitfulness has been a function, aside from the high quality of the scholars who have worked on it, of the 'lab like' conditions that the two regions' economic development trajectories apparently display: two peripheral regions of the post-Second World War international capitalist system, both of which tried to break into the industrialized, developed club of nations, and one of which succeeded and the other one, by-and-large, has failed. Can the former's success be emulated?

Such synchronic, divergent trajectories offer an almost irresistible temptation to scholars to plunge into analyses of East Asia's development success; to create a 'blueprint' for development based on the conclusions of such analyses; and to adapt the blueprint to other regional politico-economic conditions in say Latin America, Africa or South Asia. My main critique of this work is that at times it reads like a 'cut-and-paste' treatment of the subject matter in the sense of its being offered to readers as "a new path for Latin American development led by the state." These two regions' very different macro-historical trajectories (in terms of geopolitical, historical and factor endowments' conditions) mean that the policy experience of one cannot be extrapolated to the other one expecting similar results. Using the experience of East Asia growth and development as a mirror for Latin America is nonetheless useful to raise awareness that there is more than one path to capitalist success. This is particularly relevant since the global 2008 financial and economic bust of the Anglo-American version of capitalist success based on free markets and low regulation.

F. E. González (ه)

Politics and Latin American Studies, Johns Hopkins University SAIS, Washington, DC, USA

e-mail: fgonzalez@jhu.edu 